\title{
Comparitive Study on Coconut Water, Carbohydrate Electrolyte Sports Drink and Sodium Enriched Coconut Drink on Measures of Hydration and Physical Performance in Athletes
}

\author{
Apala Chaubey ${ }^{1}$, Mahak Sharma ${ }^{2}$, Barkha Bhatnagar $^{3}$ \\ ${ }^{I}$ MSc Student, Department of Nutrition and Dietetics, Manav Rachna International University, Faridabad. \\ India. Email ID: apalachaubey3011@gmail.com \\ ${ }^{2}$ Assistant Professor, Department of Nutrition and Dietetics, Manav Rachna International University, \\ Faridabad.India. \\ ${ }^{3}$ Associate Professor, Department of Nutrition and Dietetics, Manav Rachna International University, \\ Faridabad. India. \\ Corresponding Author: Apala Chaubey
}

\begin{abstract}
Coconut water which contain sodium, chloride, potassium and glucose as a rehydration fluid. Recently, attention has been given to coconut water, a natural attentive to manufactured sports drink, within initial evidence indicating efficacy with regard to maintaining hydration. The study aim to compare coconut water, sodium enriched coconut water and carbohydrate electrolyte sport drink and sodium enriched coconut drink on measures of hydration and physical performance of athletes. This is a comparative study conducted in NIT, Faridabad. The purposive sampling was done to select 8 male adults (18-30) years, athletes. Anthropometric measurement and biochemical measurements were measured by using standardized process. Blood pressure and heart rates were measured by electric BP machine. The results revealed that after three hours of dehydrating exercise test, a physical performance test was conducted by using treadmill. Regarding treadmill performance, mean and standard deviation of total exercise time in Plain water was 43.62 \pm 5.92 , coconut water 44.00 \pm 5.65 , carbohydrate electrolyte sports drink 43.75 \pm 5.70 , and sodium enriched olive coconut drink was $44.25 \pm 5.35$ but the difference was not statistically significant. The study concluded that the sodium enriched coconut drink has a better effect on the performance as compared to other drinks but differences were not so, more sample can be included to have better results.
\end{abstract}

Keywords: Coconut, Olives, Rehydration, Sodium.

\section{Introduction}

Coconut water is naturally occurring and is very rich in potassium, contain sodium chloride and carbohydrate, coconut water may be used as oral rehydration aid to replace fluid loss. Coconut water has reported to provide hydrating effects similar to those of carbohydrate - electrolyte sport drink. It also has an antioxidant property. Sports drink is ubiquitous within the recreational and competitive fitness and sporting world. Most manufactured and artificially flavored carbohydrate -electrolyte sport beverage ${ }^{(1)}$. The antioxidant ability of coconut water was recently studied by a few authors, reflect. The increasing interest in the nutraceutical properties of natural products. ${ }^{(2)}$ Recently, attention has been given to coconut water, a natural attentive to manufactured sports drink, within initial evidence indicating efficacy with regard to maintaining hydration. The amount of carbohydrate in a drink will depend on circumstances. High carbohydrate concentrations will delay gastric emptying, thus reducing the amount of fluid that is available for absorption very high concentrations will result in secretion of water into the intestine and thus actually increase the danger of dehydration. However, where there is a need to supply an energy source during exercise, increasing the carbohydrate content of drinks will increase the delivery of carbohydrate to the site of absorption in the small intestine. As carbohydrate concentration increases, the volume of fluid emptied from the stomach is reduced but the amount of carbohydrate available for absorption is increased ${ }^{(3)}$. Rehydration after exercise not only replacement of volume loss but also replacement of electrolyte primarily lost of sodium loss in sweat. Such sodium loss can result in complete rehydration and many predispose the athlete to heat cramp during subsequent exercise ${ }^{(4)}$. Rapid and complete restoration of fluid balance after exercise is an important part of the recovery process. Heavy sweating during exercise can cause body fluid losses in excess of 1 liter per hour. Individual must ingest sufficient fluid to recover from their dehydrated state. Rehydration after exercise not only replacement of volume loss but also replacement of electrolyte primarily lost of sodium loss in sweat. Such sodium loss can result in complete rehydration and many predispose the athlete to heat cramp during subsequent exercise $^{(5)}$. 


\section{Methodology}

The present study was conducted to compare water, coconut water and carbohydrate electrolyte sports drink on measures of hydration and physical performance of athletes. The study was conducted in NIT Faridabad, Haryana, and North India. Purposive sampling was done to select 8 adult (18-30 years) athlete subjects of endurance sport to conduct the present study. Inclusion criteria was, subject engaged in a program of regular exercise for a minimum of past six months, no difficulty in walking and running, do not use any new supplements, males were included in the study and subject willing to participate in the study. Exclusion criteria was - females were excluded, those who were not willing to participate, Smokers, Reported the history of cardiovascular, metabolic, neurological, orthopedic disorder, use of any new nutritional supplements. The standardized questionnaire entitled as Physical Activity Readiness Questionnaire [PARQ], was used to collect health history. Anthropometric measurements were done by using standardized tools, which include weight via digital scale. The biochemical measurements were measured by standardized process. The biochemical parameters include Urine gravity Blood Pressure and head rate was measured by electric BP machine. The study was divided into 3 phases:

1) Dehydration phase

2) Hydration phase

3) Physical performance test

\section{DEHYDRATION PHASE}

The dehydrating exercise consisted of two stages - 30-minute bouts of walking/jogging, interspersed with a 10 minute rest period. Specifically, subjects walked/jogged at 2, 3, 4, 5, 6 and 7 miles per hour on a motorized treadmill, using a grade of $0 \%$. Five minutes of exercise was performed at each speed. Following the initial 30 minutes of exercise, a 10-minute break was allowed, during which time subjects walked around and/or remained seated. Subjects then repeated the above sequence of speeds for an additional 30 minutes of exercise. Hence, a total of 60 minutes of exercise was performed within the 70 minute period.

\section{HYDRATION PHASE}

Subjects received their assigned condition (beverage), cross-over assignment to one of the following four conditions - plain water, coconut water coconut water, carbohydrate-electrolyte sport drink and sodium enriched coconut drink. The amount of each beverage was determined based on the total amount of body mass lost during the dehydrating exercise protocol using the equation: $1300 \mathrm{~mL} \cdot \mathrm{kg}-1 \times \mathrm{kg}$ loss $=$ amount of beverage consumed $(\mathrm{mL})$. Subjects were allowed 60 minutes to consume the entire volume of beverage. Each condition was consumed on a different test day, with a minimum of five days separating test visits.

\section{EXERCISE PERFORMANCE PHASE}

Three hours after the completion of the dehydrating exercise test (and two hours after subjects consumed their assigned condition), a test of physical performance was conducted using a treadmill as previously done. Specifically, subjects began walking on a motorized treadmill at a self-selected comfortable speed ( $0 \%$ grade) for five minutes. At the conclusion of the five-minute period, the actual performance test began. The protocol involved an increase in intensity every three minutes. While the speed of the treadmill remained constant at 4.2 miles per hour throughout the test, the grade increase in the following manner: min 1-3, $0 \%$; $\min 4-6,2.5 \%$; $\min 7-9,5 \%$; $\min 10-12,7.5 \%$; $\min 13-15,10 \%$; $\min 16-18,12.5 \%$; $\min 19-21,15 \%$. Subjects exercised until volitional exhaustion and the total exercise time was recorded.

\section{Experimental Analysis}

\section{Result And Discussion}

Table 1. Body mass of athletes before and after dehydrating exercise

\begin{tabular}{|c|c|c|c|c|c|}
\hline STAGES & $\begin{array}{l}\text { PLAIN } \\
\text { WATER }\end{array}$ & $\begin{array}{l}\text { COCONUT } \\
\text { WATER }\end{array}$ & $\begin{array}{l}\text { CARBOHYDRATE } \\
\text { ELECTROLYTE } \\
\text { SPORTS DRINK }\end{array}$ & $\begin{array}{l}\text { SODIUM } \\
\text { ENRICHED } \\
\text { COCOCNUT } \\
\text { DRINK } \\
\end{array}$ & $\begin{array}{l}\text { P-value } \\
\text { (ANOVA) }\end{array}$ \\
\hline $\begin{array}{l}\text { Pre-dehydrating } \\
\text { performance test }\end{array}$ & $60.9 \pm 6.24$ & $60.97 \pm 6.24$ & $60.9 \pm 6.24$ & $60.9 \pm 6.24$ & \multirow[t]{5}{*}{0.00} \\
\hline $\begin{array}{ll}\text { Immediately } \\
\text { dehydrating test }\end{array} \quad$ post & $59.6 \pm 6.3$ & $59.4 \pm 6.2$ & $59.6 \pm 6.3$ & $59.6 \pm 6.3$ & \\
\hline 1 hour post dehydrating test & $62.1 \pm 6.61$ & $62.13 \pm 6.57$ & $62.1 \pm 6.61$ & $62.1 \pm 6.61$ & \\
\hline 2 hour post dehydrating test & $61.9 \pm 0.0$ & $62.41 \pm 7.2$ & $61.9 \pm 0.0$ & $61.9 \pm 0.0$ & \\
\hline 3 hour post dehydrating test & $61.2 \pm 6.64$ & $61.64 \pm 0.0$ & $61.2 \pm 6.64$ & $61.2 \pm 6.64$ & \\
\hline
\end{tabular}

Table no. 1 described the body weight of target subjects. There were four stages in which - plain water, coconut water, carbohydrate electrolyte drink and sodium enriched coconut drink was given to the subjects. During each experimental day, the Body Weight was measured in 5 stages - pre-dehydrating exercise test, 
immediately post dehydrating test, one hours post dehydrating test, Two hours post dehydrating test and Three hours post dehydrating test.

During $1^{\text {st }}$ experimental day of $1^{\text {st }}$ week, the mean and standard deviation of body weight of the target group during pre dehydrating phase was $60.9 \pm 6.24$. After dehydration treadmill test the mean and standard deviation of body mass was reduced by $59.6 \pm 6.3$. After $1^{\text {st }}$ hour post dehydrating exercise test the mean and standard deviation of body mass was raised by $62.1 \pm 6.61$ because of rehydration fluid (PLAIN WATER) given just after treadmill test. In $2^{\text {nd }}$ hour of dehydrating exercise test the mean and standard was $62.41 \pm 7.2$. In $3^{\text {rd }}$ hour of post dehydrating test the mean and standard deviation was $61.64 \pm 6.64$.

During the $2^{\text {nd }}$ experimental day of $2^{\text {nd }}$ week, the pre dehydrating exercise test, the mean and standard deviation of body mass was $60.97 \pm 0.0$. Immediately after exercise the mean and standard deviation was $60.9 \pm 6.24$ it shows that the subject's body mass was decreased. In $1^{\text {st }}$ hour of post dehydrating exercise test, the mean and standard deviation was $62.13 \pm 6.57$ because of rehydration fluid (COCONUT WATER) given just after treadmill test. In $2^{\text {nd }}$ hour of dehydrating exercise test the mean and standard was $62.41 \pm 7.2$. In $3^{\text {rd }}$ hour of post dehydrating test the mean and standard deviation was $61.64 \pm 6.64$.

During $3^{\text {rd }}$ experimental day of $3^{\text {rd }}$ week, the pre dehydrating exercise test, the mean and standard deviation of body mass was $60.97 \pm 0.0$. Immediately after exercise the mean and standard deviation was $60.9 \pm 6.24$ it shows that the subject's body mass was decreased. In $1^{\text {st }}$ hour of post dehydrating exercise test, the mean and standard deviation was $62.13 \pm 6.57$ because of rehydration fluid (CARBOHYDRATE ELECTROLYTE DRINK) given just after treadmill test. In $2^{\text {nd }}$ hour of dehydrating exercise test the mean and standard was $61.9 \pm 7.2$. In $3^{\text {rd }}$ hour of post dehydrating test the mean and standard deviation was $61.64 \pm 6.64$.

During $4^{\text {th }}$ experiment of $4^{\text {th }}$ week, the pre dehydrating exercise test, the mean and standard deviation of body mass was $60.97 \pm 0.0$. Immediately after exercise the mean and standard deviation was $60.9 \pm 6.24$ it shows that the subject's body mass was decreased. In $1^{\text {st }}$ hour of post dehydrating exercise test, the mean and standard deviation was $62.13 \pm 6.57$ because of rehydration fluid(SODIUM ENRICHED COCONUT DRINK) given just after treadmill test. In $2^{\text {nd }}$ hour of dehydrating exercise test the mean and standard was $61.9 \pm 7.2$. In $3^{\text {rd }}$ hour of post dehydrating test the mean and standard deviation was $61.64 \pm 6.64$.

A study has done by kalman et al. (2012) stated the similar result, no differences was noted, In regard to body mass, subjects lost approximately $1.7 \mathrm{~kg}$ during the dehydrating exercise ( $2 \%$ of starting body mass), regained this amount in a similar manner following consumption of all conditions, and slowly lost approximately $1 \mathrm{~kg}$ over the subsequent two hours. However, body mass $(\mathrm{p}=0.023)$ was slightly greater with coconut water from concentrate compared $\mathrm{b}$ only to bottled water (when expressed as change from pre dehydrating exercise at 3 hours post dehydrating exercise). No other differences were noted between conditions for body mass ( $p>0.05)$.

Table 2. Urine Specific Gravity of athletes before and after dehydrating exercise

\begin{tabular}{|c|c|c|c|c|c|}
\hline Stages & Plain water & $\begin{array}{l}\text { Coconut } \\
\text { water }\end{array}$ & $\begin{array}{ll}\text { Carbohydrate } & \\
\text { electrolyte } & \text { sports } \\
\text { drink } & \end{array}$ & $\begin{array}{l}\text { Sodium } \\
\text { enriched } \\
\text { coconut } \\
\text { drink }\end{array}$ & $\begin{array}{l}\text { P-value } \\
\text { (ANOVA) }\end{array}$ \\
\hline Pre-dehydrating exercise & $1.02 \pm 0.0$ & $1.02 \pm 0.0$ & $1.03 \pm 0.00$ & $1.02 \pm 0.005$ & \multirow{3}{*}{0.00} \\
\hline $\begin{array}{l}\text { Immediately post } \\
\text { dehydrating exercise }\end{array}$ & $1.03 \pm 0.00$ & $1.03 \pm 0.00$ & $1.03 \pm 0.00$ & $1.01 \pm 0.00$ & \\
\hline $\begin{array}{l}\text { 3hour post dehydrating } \\
\text { exercise }\end{array}$ & $0.35 \pm 0.00$ & $0.35 \pm 0.00$ & $1.01 \pm 0.008$ & $1.01 \pm 0.005$ & \\
\hline
\end{tabular}

The above table 2 described the urine specific gravity of the subjects.

Normal Urine Specific Gravity can range from 1.003 to 1.020 , a value of less than 1.010 indicates relative hydration, and a value greater than 1.020 indicates relative dehydration. In the present study, there were four stages in which plain water, coconut water and carbohydrate electrolyte drink and sodium enriched coconut drink was given to the subjects. During each experiment day, the urine specific gravity was measured in 3 stages - pre-dehydrating exercise test, post dehydrating test, three hours post dehydrating test.

During the $1^{\text {st }}$ experimental day of $1^{\text {st }}$ week, the urine specific gravity was $1.020 \pm 0.0$ at pre-dehydrating exercise test stage. In second stage, immediately post dehydrating test, the urine specific gravity was increased by $1.030 \pm 0.0$. This indicates that the subjects were dehydrated. In third stage, after three hours post dehydrating test (after 3 hours of rehydration with plain water), the urine specific gravity was decreased by $1.020 \pm 0.0$.

During the $2^{\text {nd }}$ experimental day of $2^{\text {nd }}$ week, the urine specific gravity was $1.020 \pm 0.0$ at pre dehydrating exercise test stage. In second stage, immediately post dehydrating test, the urine specific gravity was increased by $1.030 \pm 0.0$ this indicates that subject was dehydrated. In third stage, after three hours post dehydrating test (after 3 hours of rehydration with coconut water), the urine specific was decreased by $1.030 \pm 0.0$. 
During $3^{\text {rd }}$ experimental day of $3^{\text {rd }}$ week, the urine specific gravity was $1.020 \pm 0.0$ at pre dehydrating exercise test stage, In second stage, the immediately post dehydrating exercise test, the urine specific gravity was increased by $1.030 \pm 0.0$ this indicates that the subject was dehydrated. In third stage, after three hour post dehydrating exercise test(after 3 hours of rehydration with carbohydrate electrolyte sports drink), the urine specific gravity was decreased by $1.01 \pm 1.008$.

During $4^{\text {th }}$ experimental day of week $4^{\text {th }}$ the urine specific gravity was $1.020 \pm 0.0$ at pre dehydrating exercise test. In second stage, after immediately post dehydrating exercise test, the urine specific gravity was increased by $1.030 \pm 0.0$ this indicates that the subjects was dehydrated. In second stage, three hours post dehydrating exercise test (after 3 hours of rehydration with sodium enriched coconut drink), the urine specific gravity was decreased by $1.010 \pm 1.005$.

A study has done by kalman et al. (2012) stated the similar result, no differences were noted between conditions for urine specific gravity, with this measure relatively constant and within the normal range over the measurement period $(\mathrm{p}>0.05)$.

Table 3. Heart Rate of athletes before and after dehydrating exercise

\begin{tabular}{|c|c|c|c|c|c|}
\hline STAGES & $\begin{array}{l}\text { PLAIN } \\
\text { WATER }\end{array}$ & $\begin{array}{l}\text { COCONUT } \\
\text { WATER }\end{array}$ & $\begin{array}{l}\text { CARBOHYDRATE } \\
\text { ELECTROLYTE } \\
\text { SPORTS DRINK }\end{array}$ & $\begin{array}{l}\text { SODIUM } \\
\text { ENRICHED } \\
\text { COCONUT } \\
\text { DRINK }\end{array}$ & $\begin{array}{l}\text { P-value } \\
\text { (ANOVA) }\end{array}$ \\
\hline $\begin{array}{l}\text { Pre dehydrating } \\
\text { exercise test }\end{array}$ & $67.62 \pm 6.13$ & $66.87 \pm 6.05$ & $67.62 \pm 6.13$ & $67.6 \pm 6.13$ & \multirow{4}{*}{0.00} \\
\hline $\begin{array}{ll}\text { Immediately post } \\
\text { dehydrating } \\
\text { exercise test }\end{array}$ & $104.5 \pm 9.79$ & $\begin{array}{ll}109.87 & \pm \\
9.53 & \end{array}$ & $104.5 \pm 9.79$ & $104.5 \pm 9.7$ & \\
\hline $\begin{array}{ll}\begin{array}{l}\text { 3hour } \\
\text { dehydrating } \\
\text { exercise test }\end{array} & \text { post } \\
\end{array}$ & $\begin{array}{l}72.37 \quad \pm \\
10.51\end{array}$ & $\begin{array}{l}72.37 \quad \pm \\
10.51\end{array}$ & $72.3 \pm 10.51$ & $72.37 \pm 10.51$ & \\
\hline $\begin{array}{l}\text { Immediately post } \\
\text { performance } \\
\text { exercise test }\end{array}$ & $100.72 \pm 8.82$ & $99.50 \pm 9.01$ & $102.72 \pm 9.23$ & $100.72 \pm 8.23$ & \\
\hline
\end{tabular}

Table no. 3 depicted the heart rate of athletes before and after dehydrating exercise. There were four stages in which - plain water, coconut water, carbohydrate electrolyte drink and sodium enriched coconut drink was given to the subjects. During each experimental day, the heart rate was measured in 4 stages - predehydrating exercise test, immediately post dehydrating test, three hours post dehydrating test and immediately post performance test.

During the $1^{\text {st }}$ experimental day of $1^{\text {st }}$ week, the heart rate was $67.62 \pm 6.13$ at pre-dehydrating exercise test stage. In second stage, immediately post dehydrating test, the heart rate was increased by104.5 \pm 9.79 .In third stage, after three hours post dehydrating test (after 3 hours of rehydration with plain water), the heart rate was $72.37 \pm 10.51$. In $4^{\text {th }}$ stage, immediately post performance exercise test the heart rate was $100.72 \pm 8.82$

During the $2^{\text {nd }}$ experimental day of $2^{\text {nd }}$ week, the heart rate was $67.62 \pm 6.13$ at pre-dehydrating exercise test stage. In second stage, immediately post dehydrating test, the heart rate was increased by109.5 \pm 9.53 .In third stage, after three hours post dehydrating test (after 3 hours of rehydration with coconut water), the heart rate was $72.37 \pm 10.51$. In $4^{\text {th }}$ stage, immediately post performance exercise test the heart rate was $99.50 \pm 9.01$

During the $3^{\text {rd }}$ experimental day of $3^{\text {rd }}$ week, the heart rate was67.62 \pm 6.13 at pre-dehydrating exercise test stage. In second stage, immediately post dehydrating test, the heart rate was increased by104.5 \pm 9.79.In third stage, after three hours post dehydrating test (after 3 hours of rehydration with carbohydrate electrolyte sports drink), the heart rate was $72.3 \pm 10.51$. In $4^{\text {th }}$ stage, immediately post performance exercise test the heart rate was $102.72 \pm 8.23$

During the $4^{\text {th }}$ experimental day of $4^{\text {th }}$ week, the heart rate was $67.6 \pm 6.13$ at pre-dehydrating exercise test stage. In second stage, immediately post dehydrating test, the heart rate was increased by104.5 \pm 9.7.In third stage, after three hours post dehydrating test (after 3 hours of rehydration with sodium enriched coconut drink), the heart rate was $72.37 \pm 10.51$. In $4^{\text {th }}$ stage, immediately post performance exercise test the heart rate was 100.72 \pm 8.23 . A study has done by kalman et al. (2012) stated the similar result, no differences were noted between conditions for heart rate, $(\mathrm{p}>0.05)$.

Table 4. Systolic Blood Pressure of athletes before and after dehydrating exercise

\begin{tabular}{|l|l|l|l|l|l|}
\hline STAGES & PLAIN & COCONUT & CARBOHYDRATE & SODIUM & P-value \\
\hline
\end{tabular}




\begin{tabular}{|c|c|c|c|c|c|}
\hline & WATER & WATER & $\begin{array}{l}\text { ELECTROLYTE } \\
\text { SPORTS DRINK }\end{array}$ & $\begin{array}{l}\text { ENRICHED } \\
\text { COCONUT } \\
\text { DRINK }\end{array}$ & (ANOVA) \\
\hline Pre-dehydrating exercise test & $117.0 \pm 3.80$ & $116.25 \pm 3.80$ & $117.3 \pm 2.55$ & $115.25 \pm 3.84$ & \multirow{3}{*}{0.00} \\
\hline 3 hour post dehydrating test & $114.5 \pm 6.41$ & $117.25 \pm 9.16$ & $114.87 \pm 2.69$ & $121.75 \pm 5.33$ & \\
\hline $\begin{array}{l}\text { Immediately post performance } \\
\text { exercise test }\end{array}$ & $136.5 \pm 8.75$ & $117.25 \pm 9.16$ & $139.12 \pm 4.48$ & $137.5 \pm 6.80$ & \\
\hline
\end{tabular}

Table no. 4 depicted the Systolic Blood Pressure of athletes before and after dehydrating exercise. There was three stages in which - plain water, coconut water and carbohydrate electrolyte drink and sodium enriched coconut drink were given to the subjects. During each experimental day, the systolic was measured in 4 stages - pre-dehydrating exercise test, post dehydrating test, three hours post dehydrating test.

During the $1^{\text {st }}$ experimental day of $1^{\text {st }}$ week, the systolic blood pressure was $117.0 \pm 3.80$ at predehydrating exercise test stage. In second stage, immediately post dehydrating test, the systolic pressure was increased by $140.75 \pm 7.16$. In third stage, after 3 hours post dehydrating test (after 3 hours of rehydration with plain water), the systolic pressure was maintained by $114.5 \pm 6.41$. Immediately post performance exercise test the systolic pressure was increased by $136.5 \pm 8.75$

During the $2^{\text {nd }}$ experimental day of $2^{\text {nd }}$ week, the systolic was $116.25 \pm 3.80$ at pre-dehydrating exercise test stage. In second stage, immediately post dehydrating test, the systolic pressure was increased by 141.10 \pm 7.10 . In third stage, after 3 hours post dehydrating test (after 3 hours of rehydration with coconut water), the systolic pressure was maintained by $117.25 \pm 9.16$, in normal range. Immediately post performance exercise test the systolic pressure was increased by $138.25 \pm 7.9$

During the $3^{\text {rd }}$ experimental day of $3^{\text {rd }}$ week, the systolic pressure was $115.25 \pm 3.84$ at pre-dehydrating exercise test stage. In second stage, immediately post dehydrating test, the systolic pressure was increased by140.75 \pm 5.33 . In third stage, after 3 hours post dehydrating test (after 3 hours of rehydration with coconut water), the systolic pressure was maintained by $117.25 \pm 9.16$. Immediately post performance exercise test the systolic pressure was increased by $140.12 \pm 6.49$

During the $4^{\text {th }}$ experimental day of $4^{\text {th }}$ week, the systolic was $115.25 \pm 3.84$ at pre-dehydrating exercise test stage. In second stage, immediately post dehydrating test, the systolic pressure was increased by 141.10 \pm 7.10 . In third stage, after 3 hours post dehydrating test (after 3 hours of rehydration with coconut water), the systolic pressure was maintained by $121.75 \pm 5.33$. Immediately post performance exercise test the systolic pressure was increased by $137.5 \pm 6.80$ A study has done by kalman et al. (2012) stated the similar result; no differences were noted between conditions for systolic blood pressure $(\mathrm{P}>0.05)$.

Table 5. Diastolic Blood Pressure of athletes before and after dehydrating exercise

\begin{tabular}{|l|l|l|l|l|l|}
\hline STAGES & $\begin{array}{l}\text { PLAIN } \\
\text { WATER }\end{array}$ & $\begin{array}{l}\text { COCONUT } \\
\text { WATER }\end{array}$ & $\begin{array}{l}\text { CARBOHYDRATE } \\
\text { ELECTROLYTE } \\
\text { SPORTS DRINK }\end{array}$ & $\begin{array}{l}\text { SODIUM } \\
\text { ENRICHED } \\
\text { COCONUT } \\
\text { DRINK }\end{array}$ & $\begin{array}{l}\text { P-value } \\
\text { (ANOVA) }\end{array}$ \\
\hline Pre-dehydrating exercise test & $70.0 \pm 3.89$ & $79.25 \pm 9.49$ & $83.25 \pm 9.09$ & $69.00 \pm 2.32$ & \\
\hline $\begin{array}{l}\text { Immediately post } \\
\text { dehydrating exercise test }\end{array}$ & $\begin{array}{l}87.87 \\
\pm 12.01\end{array}$ & $96.12 \pm 8.91$ & $94.62 \pm 4.20$ & $86.00 \pm 7.21$ & \multirow{2}{*}{0.00} \\
\hline 3 hour post dehydrating test & $81.62 \pm 12.4$ & $72.87 \pm 6.22$ & $74.12 \pm 9.35$ & $81.62 \pm 12.4$ & \\
\cline { 1 - 3 } $\begin{array}{l}\text { Immediately post } \\
\text { performance exercise test }\end{array}$ & $\begin{array}{l}84.25 \pm \\
13.93\end{array}$ & $84.25 \pm 13.93$ & $87.00 \pm 10.44$ & $84.25 \pm 13.9$ & \\
\hline
\end{tabular}

Table no.1.5 depicted the Diastolic Blood Pressure of athletes before and after dehydrating exercise. There was four stages in which - plain water, coconut water and carbohydrate electrolyte drink and sodium enriched coconut drink were given to the subjects. During each experiment day, the diastolic pressure was measured in 4 stages - pre-dehydrating exercise test, post dehydrating test, three hours post dehydrating test.

During the $1^{\text {st }}$ experimental day of $1^{\text {st }}$ week, the systolic pressure was $70.0 \pm 3.89$ at pre-dehydrating exercise test stage. In second stage, immediately post dehydrating test, the diastolic pressure was increased by $87.7 \pm 12.01$. In third stage, after 3 hours post dehydrating test (after 3 hours of rehydration with plain water), the diastolic pressure was maintained by $81.62 \pm 12.4$. Immediately post performance exercise test the diastolic pressure was increased by $84.25 \pm 13.93$

During the $2^{\text {nd }}$ experimental day of $2^{\text {nd }}$ week, the diastolic pressure was $79.25 \pm 4.94$ at pre-dehydrating exercise test stage. In second stage, immediately post dehydrating test, the diastolic pressure was increased by $96.12 \pm 8.91$. In third stage, after 3 hours post dehydrating test (after 3 hours of rehydration with coconut water), the diastolic pressure was maintained by $72.87 \pm 6.22$. Immediately post performance exercise test the diastolic pressure was increased by $84.25 \pm 13.93$ 
During the $3^{\text {rd }}$ experimental day of $3^{\text {rd }}$ week, the diastolic pressure was $83.25 \pm 9.09$ at pre-dehydrating exercise test stage. In second stage, immediately post dehydrating test, the diastolic pressure was increased by94.62 \pm 4.20 . In third stage, after 3 hours post dehydrating test (after 3 hours of rehydration with coconut water), the diastolic pressure was maintained $74.12 \pm 9.35$. Immediately post performance exercise test the diastolic pressure was increased by $87.00 \pm 10.44$.

During the $4^{\text {th }}$ experimental day of $4^{\text {th }}$ week, the systolic was $69.00 \pm 2.32$ pre-dehydrating exercise test stage. In second stage, immediately post dehydrating test, the systolic pressure was increased by $86.00 \pm 7.21$ In third stage, after 3 hours post dehydrating test (after 3 hours of rehydration with coconut water), the systolic pressure was maintained by $81.62 \pm 12.4$. Immediately post performance exercise test the systolic pressure was increased by $84.25 \pm 13.9$ A study has done by kalman et al. (2012) stated the similar result; no differences were noted between conditions for diastolic blood pressure, $(\mathrm{p}>0.05)$.

Table 6. Total Time of athletes immediately after performance test

\begin{tabular}{|l|l|l|}
\hline Stages & Performance test & $\begin{array}{l}\text { P-value } \\
\text { (ANOVA) }\end{array}$ \\
\hline Plain water & $43.62 \pm 5.92$ & \multirow{2}{*}{$\mathbf{0 . 9 9 6}$} \\
\hline Coconut water & $44.00 \pm 5.65$ & \\
\hline Carbohydrate electrolyte sports drink & $43.75 \pm 5.70$ & \\
\hline Sodium enriched coconut drink & $44.25 \pm 5.35$ & \\
\hline
\end{tabular}

Table no. 6 depicted total time immediately after performance test. After three hours of dehydrating exercise test, a physical performance test was conducted by using treadmill. Regarding treadmill performance, mean and standard deviation of total exercise time in Plain water 43.62 \pm 5.92 , coconut water $44.00 \pm 5.65$, carbohydrate electrolyte sports drink $43.75 \pm 5.70$, sodium enriched coconut drink $44.25 \pm 5.35$ but the difference was not statistically significant.

\section{Conclusion}

The study concluded that the sodium enriched coconut drink had a better effect on the performance test as compared to other drinks but differences were not statistically significant so, more sample size can be included to have better results. The limitation of the study might be that the intervention of coconut water was done only once, one time during exercise.

\section{Bibliography}

[1] Reddy, P. and M. lakshmi, Coconut water properties, uses, and nutritional benefits in health and disease review, Journal of current clinical medicine and laboratory biochemistry,10(2),2003,11-21.

[2] Mantena, S. Jagadish, Badduri, R. Siripurapu, K and M. Unnikrishnan, In vitro evaluation of antioxidant properties of Cocos nucifer, Journal of current clinical medicine and laboratory biochemistry,47(4),2011,20-25.

[3] Asker, E. Jeukendrup, Sophie, C and Killer, The Myths Surrounding Pre-Exercise Carbohydrate Feeding, Journal of the International Society of Sports Nutrition, 57(2),2010,18-25.

[4] Maughan.J and Shirreffs, Fluid and electrolytes loss and replacement in exercise, In: Oxford textbook of sports medicine, 25(1), 1998,53-74.

[5] Michael F. Bergeron, FACSM,Georgia Prevention Institute, Department of Pediatrics, Medical College of Georgia, Augusta, Georgia, 13(3),2000, 452-460

[6] Douglas, Kalman, S. Samantha, Feldman, Krieger, R. and R. Bloome, Comparison of coconut water and a carbohydrate-electrolyte sport drink on measures of hydration and physical performance in exercise-trained me, Journal of the International Society of Sports Nutrition, 9(1), 2012, 22-25

Apala Chaubey. "Comparitive Study on Coconut Water, Carbohydrate Electrolyte Sports Drink and Sodium Enriched Coconut Drink on Measures of Hydration and Physical Performance in Athletes." IOSR Journal of Sports and Physical Education (IOSR-JSPE) 4.3 (2017): 46-51. 